Public Health Genomics
Public Health Genomics 2017;20:116-125

DOI: $10.1159 / 000478253$
Received: May 31, 2017

Accepted: June 9, 2017

Published online: July 20, 2017

\title{
Exosomes: A Cancer Theranostics Road Map
}

\author{
Angeliki Panagiotara $^{a}$ Athina Markou $^{b}$ Evi S. Lianidou ${ }^{b}$ George P. Patrinos ${ }^{a, c}$ \\ Theodora Katsila ${ }^{a}$ \\ a Department of Pharmacy, School of Health Sciences, University Campus, Rion, University of Patras, Patras, \\ and ${ }^{b}$ Analysis of Circulating Tumor Cells Lab, Department of Chemistry, University of Athens, Athens, Greece; \\ 'Department of Pathology, College of Medicine and Health Sciences, United Arab Emirates University, \\ Al Ain, United Arab Emirates
}

\section{Keywords}

Microfluidics · Cancer · Public health · Exosomes · Liquid biopsies

\begin{abstract}
Interindividual variability is yet to be fully characterized, and for this, optimum patient stratification and companion diagnostics are still lacking. Especially when complex disease phenotypes and/or polygenic diseases are considered, patient monitoring and disease management become rather challenging, while acquired resistance to therapy and/or toxicity events are among the unmet needs in the clinic. No doubt, biomarkers are of great importance to disease management and tailor-made theranostics. Microfluidics has gathered great attention lately, mostly due to its low-invasive nature compared to tissue biopsies. Low invasiveness becomes greatly advantageous for microfluidics practices as the latter mirror cell biology revolutionizing cancer diagnostics and management. Recent advances in microfluidics hold the promise of robust clinical diagnostics after they have demonstrated effective exosome separation. We feel that microfluidics-based exosome isolation techniques, if costeffective, could be implemented in the clinic and/or resource-scarce settings. This article (a) discusses exosomes,
\end{abstract}

\section{KARGER}

๑ 2017 S. Karger AG, Basel

E-Mail karger@karger.com

www.karger.com/phg (b) comments on the first microfluidic advances in the field of cancer theranostics, (c) presents such advances in exosomes as complementary to liquid biopsies with an emphasis on circulating tumor cells, and (d) proposes a road map for future developments.

(c) 2017 S. Karger AG, Basel

\section{Introduction}

Tailor-made diagnostics employs molecular biomarkers to characterize and map the pathological condition of an individual, and hence, they can be divided into several subgroups on the basis of the application of interest; screening, early diagnosis, prognosis, prediction, monitoring, and companion diagnostics [1]. Such biomarkers have been utilized in cancer and have been proven to have sufficient clinical evidence to be incorporated in the European Society of Medical Oncology (ESMO; http://www. esmo.org/) guidelines [2], specifically for primary breast cancer [3], advanced breast cancer [4], metastatic nonsmall-cell-lung cancer [5], prostate cancer [6], and early colorectal cancer [7]. Predictive biomarkers and companion diagnostics have both contributed to the emergence of the field of precision medicine, which has revolution-

Theodora Katsila

Department of Pharmacy, School of Health Sciences University Campus, Rion, University of Patras GR-265 04 Patras (Greece)

E-Mail thkatsila@upatras.gr 
ized patient care in the last decade. The discovery of interindividual genomic alterations has allowed the clinician to have a better picture of interindividual cancer signature and thus, make informed decisions about effective treatment strategies.

Current analytical limitations, however, start with the nature of the sample. The invasive nature of these diagnostic procedures, which often require tissue samples, has always been an unappealing characteristic, especially in cases like brain and lung cancers, where biopsies are painful and sometimes life-threatening, while in others like pancreatic cancer the sample material is not always sufficient to confirm a diagnosis [8-10]. Furthermore, intra-tumor heterogeneity, both genetic and phenotypic, remains a challenge in obtaining a comprehensive cancer profile. Biopsies from single tissue samples can lead to the mischaracterization of tumors as a whole, given their notorious fingerprint-like variability [11].

Indeed, a traditional tissue biopsy could miss genomic variants just few centimeters away, possibly with a detrimental effect on a person's chances of survival. Moreover, given the molecular instability of the tumor, information derived from these samples is static and susceptible to inaccurate prognostic value as the cancer progresses [12]. Pathogenic variants occurring after treatment are not detected without another biopsy, sometimes long after the tumor has acquired resistance to that treatment. Metastasized tumors are particularly difficult to assess with tissue biopsies, because usually only one tumor is biopsied and analyzed, leaving tumors in other sites uncharacterized, thus missing the complete genomic cancer profile [13]. Consequently, multiregional and repeated tumor biopsies to assess tumor heterogeneity are not always practical or feasible due to the associated risks and complications as well as patient comorbidity, costs, spatial heterogeneity within the tumor, lack of safe access to the lesion, and sampling bias $[14,15]$. Therefore, there is an urgent need for noninvasive diagnostic tools, which could be used for early diagnosis, estimation of the risk for developing metastasis (prognostic information), assessing tumor heterogeneity so as to personalize treatment, tracking the patient's response to treatment and detecting the development of resistance mechanisms to the treatment (predictive information) [10].

Recent advances in microfluidics hold the promise of robust clinical diagnostics after they have demonstrated effective exosome separation. We feel that microfluidicsbased exosome isolation techniques, if cost-effective, could be implemented in the clinic and/or resourcescarce settings. This article (a) discusses exosomes, (b)

Exosomes: A Cancer Theranostics Road Map comments on the first microfluidic advances in the field of cancer theranostics, (c) presents such advances in exosomes as complementary to liquid biopsies with an emphasis on circulating tumor cells (CTCs), and (d) proposes a road map for future developments. Microfluidics, as we will discuss, holds the promise of turning current limitations and challenges into opportunities in the field of cancer theranostics (Fig. 1).

\section{Exosomes}

Exosomes are circulating vesicles in the blood stream. In 1981, Trams et al. [16] used the term "exosomes" to describe membrane-enclosed structures of variable size budding from cell membrane. Six years later, Johnstone et al. [17] used this very same term to define small vesicles $(50-100 \mathrm{~nm})$ of endosomal origin, which fuse with cell membrane and then, are secreted. It is suggested that these vesicles, along with microvesicles, have important functional roles in the intercellular communication and signaling, and this new knowledge led to a burst of interest in the field $[18,19]$. However, as was expected, without proper nomenclature, the scientific community was faced with a challenge in distinguishing microvesicles, exosomes, and extracellular vesicles (EVs), with these terms often used interchangeably by mistake. These structures vary in size, biogenesis and secretion routes and are collected with different methods [20]. In 2011, the emerging immense interest in EVs led to the establishment of the International Society for Extracellular Vesicles. It was then suggested that in the face of new advancements in the field, investigators should be encouraged to use the term "extracellular vesicles" as a generic term for the heterogeneous population of all secreted vesicles, with exosomes and microvesicles being two distinct subclasses, varying in size and biogenesis. Currently, the gold standard technique for defining and separating exosomes and microvesicles is differential centrifugation. Notwithstanding, it has many technical caveats and raises concerns as to whether this is the proper way to reliably discriminate between them [21].

Multivesicular bodies (MVB) that contain intraluminal vesicles fuse and result in exosome biogenesis. Exosomes, thus, are small EVs with a diameter in the range of 40-100 $\mathrm{nm}$. They contain a complex protein composition (tetraspanins, heat shock proteins, transcription factors, MVB synthesis proteins, MVB-associated proteins, membrane transporters, and fusion proteins), nucleic acids (mRNA, miRNA and other small noncoding

Public Health Genomics 2017;20:116-125 DOI: $10.1159 / 000478253$ 


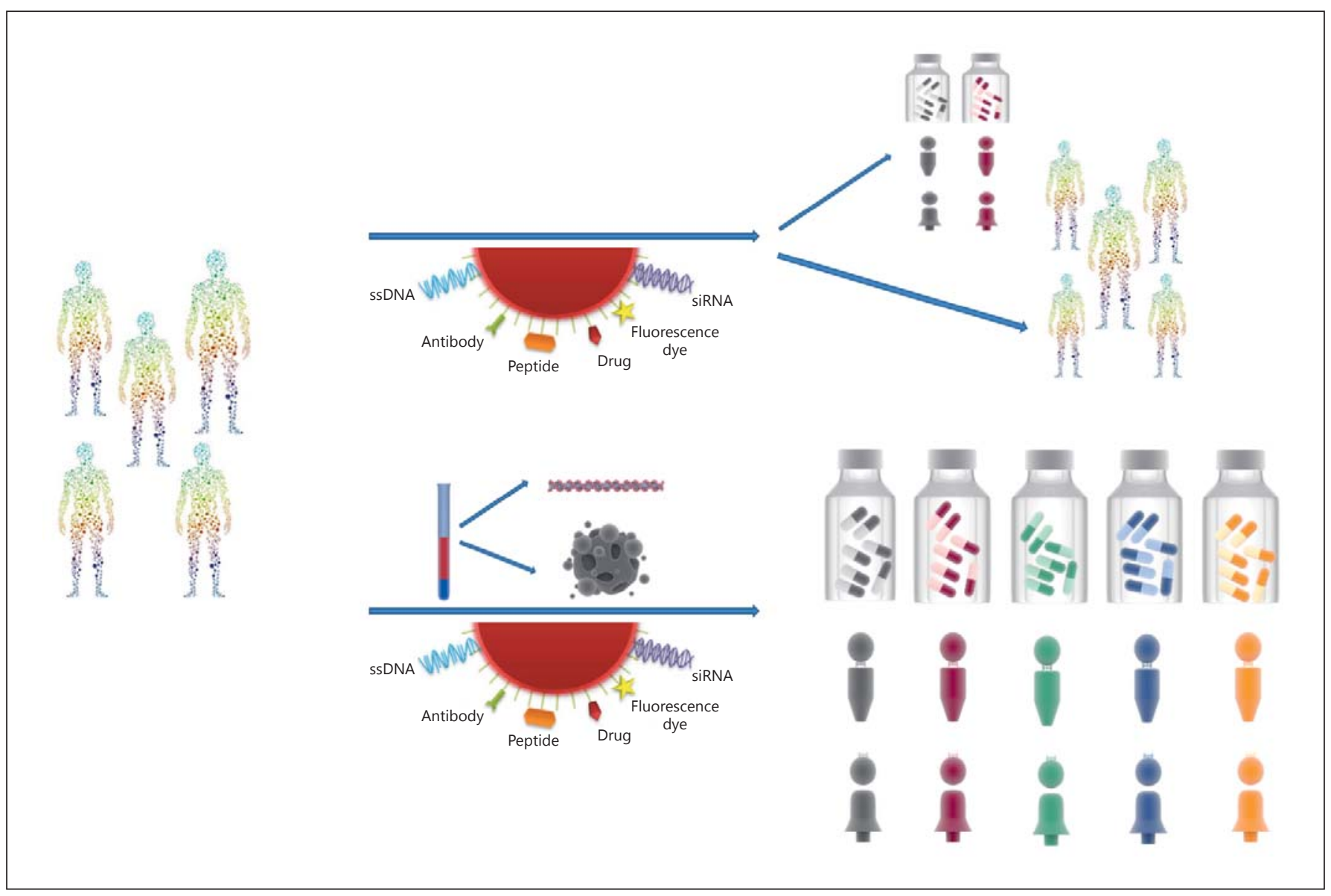

Fig. 1. Moving from molecular theranostics to a new age of microfluidics. Current theranostics aims for tailoredmade diagnostics and therapeutics, yet interindividual variability still hampers optimum disease management. Microfluidics (and, in particular, liquid biopsies and exosomes) are envisaged as the new age of theranostics delineating genotype-to-phenotype associations.

RNA molecules), and lipids, and all these components are encapsulated in a lipid bilayer. Depending on their cell origin, the exosomal cargo is functional and highly variable $[18,22]$. On the other hand, plasma membrane budding or shedding leads to the formation of microvesicles with a diameter of 100-1,000 $\mathrm{nm}$. Microvesicles are rather similar to exosomes as they encapsulate their own distinct cargo of lipids, proteins, and nucleic acids [23]. Vesiclepedia, EVpedia, and ExoCarta catalog the protein, lipid, and RNA content of both exosomes and microvesicles towards their characterization and identification [24-26]. Exosomes can be isolated from most body fluids (such as amniotic fluid, semen, ascites fluid, blood, urine, saliva, breast milk, cerebrospinal fluid, and bile), which makes them promising biomarker candidates.

\section{Microfluidic Exosome Analysis in Cancer Research}

Upon the direct membrane transfer of their cargo, EVs and exosomes, in particular, are fundamental cell signaling mediators [18]. It has been shown that miRNA can be functionally transferred to recipient cells, after its fusion with their cell membrane [19]. It is hypothesized that under cellular stress conditions, such as signaling dysregulation (a hallmark of cancer), normal vesicular trafficking is altered, and the normal protein, lipid and nucleic acid contents of exosomes are affected. In normal conditions, exosomes serve as vehicles to remove unwanted material from the cells and to transfer signaling messages to other neighboring or long-distance cells $[17,27]$. In this way, any deviation from normal conditions changes the composition of exosomes and offers a window inside the al- 
Table 1. Molecules associated with exosomes from different body fluids that are altered in different types of cancer

\begin{tabular}{|c|c|c|c|}
\hline Cancer type & Body fluid & Markers & Ref. \\
\hline Melanoma & plasma & CD63, caveolin-1 & [35] \\
\hline Prostate & serum & EGFR & [86] \\
\hline Prostate & plasma & PSMA, CD9 & [45] \\
\hline Breast, ovarian & ascites & CD24, EpCAM, miR-200a, miR-200c, miR-205 & [87] \\
\hline Lung & plasma & $\begin{array}{l}\text { EpCAM, miR-17-3p, miR-21, miR-106a, miR-146, miR-155, } \\
\text { miR-191, miR-192, miR-203, miR-205, miR-210, miR-212, } \\
\text { miR-214 }\end{array}$ & [88] \\
\hline Glioblastoma & serum & Sn RNU6-1, miR-320, miR-574-3p & [89] \\
\hline Colorectal & serum & $\begin{array}{l}\text { Let-7a, miR-1229, miR-1246, miR-150, miR-21, miR-223, } \\
\text { miR-23a }\end{array}$ & {$[90]$} \\
\hline Colorectal & plasma & - & {$[36]$} \\
\hline Acute myeloid leukemia & plasma & TGF- $\beta_{1}$ & {$[91]$} \\
\hline
\end{tabular}

tered function of the cells and the stresses they are responding to [28]. Cancer cell-derived EVs contain oncogenic molecules that are potentially functional and create a cancer-friendly environment that aids its initiation, progression, and metastasis [1,29-32].

Today, exosomes are important indicators of the molecular mechanisms involving the communication of cancer cells within the tumor microenvironment, and use of that knowledge can serve as a tool of diagnostic, prognostic, and predictive value (Table 1). There are many reviews on this topic that have effectively summed up all the molecules associated with EVs isolated from various body fluids, which have shown promising results and are altered in many diseases, both in a preclinical and/or clinical setting $[1,33,34]$. Namely, these biomarkers include miRNA markers and proteins, and they have been involved in lung, ovarian, breast, prostate, and bladder cancer, but also autoimmune diseases, liver diseases, Parkinson disease, and more. It has been proposed that not only specific molecular markers, but also exosome levels can represent tumor progression, similarly to CTCs $[35,36]$. A representative example of a traditional cancer biomarker which can be improved with the use of exosomes is that of prostate-specific antigen (PSA). Serum PSA quantification has been used for 2 decades for early detection of prostate cancer; however, this diagnostic approach is controversial, due to its inability to distinguish between PSA's malignant and benign tumor origin, thus resulting in false-positive results [37]. PSA detection and quantification in exosomes is characterized by higher specificity, when compared to blood PSA measurements, and findings suggest that both approaches can be used in conjunction $[38,39]$.

Exosomes: A Cancer Theranostics Road Map
A major challenge in the field of microfluidics refers to the isolation, analysis, and characterization of exosomes and the standardization of the methodologies used. Exosomes are usually separated from other EVs by differential centrifugation, which is based on their variable size, solubility, and buoyant density. Additional purification can be achieved by immunoabsorption, followed by imaging and biochemical techniques to further characterize them [40]. Nevertheless, ultracentrifugation that is most often used in basic research for EV isolation seems not that suitable in clinical practice, because it is characterized by low throughput and purity and depends on the operator, while high purity exosomes are particularly important for downstream analyses [1, 22]. Several other isolation methods have also been developed, such as immunocapture, size exclusion chromatography, and commercially available precipitation agents, yet ultracentrifugation dominates basic research strategies $[15,21,41]$. Following the successful isolation and identification of exosomes, downstream analytical assays can be implemented, such as the quantification of their protein content or analysis of their miRNA profile. Exosome miRNA is intact in blood samples, because the lipid bilayer protects it from circulating RNases, offering a major advantage compared to circulating tumor DNA, which requires rapid handling procedures. Tumour-specific proteins can also be detected in isolated exosomes, even though they are not as easily manageable, owing to their highly heterogeneous nature and the difficulty to collect and handle them, when compared to miRNA [42].

Notably, there are several methodologies with which exosome levels can be measured directly without former isolation: protein arrays [43], nano-plasmonic-based

Public Health Genomics 2017;20:116-125 DOI: $10.1159 / 000478253$ 
technologies [44], and flow cytometry [22, 40]. Although all are more or less equally effective towards exosome quantification, clinical implementation requires cost-effectiveness, precision, accuracy, and reproducibility. Capello et al. [34] commented that exosome measurement alone is not enough for distinguishing between cancer types and painting the complete landscape of cancer in the body, and for this, complementary methodologies should be designed and applied instead. Others argue that exosome detection seems sufficient for early diagnosis and follow-up. No doubt, lively discussions on the matter can be only advantageous for the field and best practices to be employed.

\section{Microfluidic Exosome Analysis in the Clinic}

We feel that clinical implementation requirements are highly demanding, and for this, techniques, protocols, and workflows that are highly reproducible, sensitive, specific, user- and cost-friendly need to be standardized for isolation and downstream analyses [1]. Although standard operating procedures need to be optimized, exosomes offer many advantages over traditional tissue biopsies that are currently implemented in cancer diagnostics. Firstly, they can be detected in the serum as they detach from the endothelium into the circulation, and they can provide clinicians with a noninvasive biopsy. Secondly, since they contain molecular information about the parental cell, they represent a picture of that cell, aiding us in the detection of traditional and novel biomarkers of cancer. The latter is particularly important, because exosomes act as a "lifeboat" for these molecules, which are surrounded by the lipid bilayer and protected from the extracellular proteinases and nucleases, thus allowing their detection at lower concentrations, compared to traditional blood biopsies. Furthermore, exosome content analysis is specific for the cell in question, because they contain the molecular signature of the parental cell, be it healthy or cancerous. With the development of new techniques for the isolation of each type of exosome [45], we will be able to pinpoint their origin and fully develop their potential for personalized and cutting-edge diagnostics.

Evidently, the most important challenge in translating exosomes to suitable clinical biomarkers is the lack of consensus regarding the standards of sample collection, processing and analysis [46]. It seems that the technical variations in the isolation and downstream analysis of exosomes have prevented the direct collection, handling, and comparison of data. As is expected, this is causing delay in the search for efficient new biomarkers, so standardization protocols are required urgently. Specifically, ultracentrifugation, the current gold standard technique in the isolation of exosomes, is not easily applicable in a clinical laboratory, because it requires long processing time, it is low-throughput, irreproducible, and often results in the isolation of low-purity exosomes [1, 15, 22]. Furthermore, protein detection even in purified exosomes is very challenging, due to their variable nature [42].

Moreover, another issue that needs to be discussed is the confusing nomenclature that pesters the field. Lack of precision in the nomenclature is mostly attributed to the lack of detail in procedures followed by researchers [33]. The terms "exosomes" and "microvesicles" are often used interchangeably, because most studies have not clearly defined the origins of EVs under study, which has led to the current confusion in the literature [47]. However, researchers are not to blame to a certain extent, because the physiological functions of exosomes and microvesicles are still largely unknown, and so it seems that differences in their characteristics and properties that are currently available are not enough to distinguish them.

Even when these scientific and technical challenges are effectively overcome, exosomes as a diagnostic tool should reach an evidence level sufficient for biomarker validation. Currently, there are many published biomarkers in the literature that seem to be of therapeutic value; nevertheless, few of them are introduced into the clinic and are utilized in the decision-making process, especially when it comes to predictive biomarkers and companion diagnostics. Most of the time this is due to analytical, technical and regulatory limitations, as well as insufficient clinical validity and utility and reimbursement issues $[2,48]$.

To handle these issues, we have to accurately set the standards for ideal biomarkers. First, there needs to be sufficient scientific, preclinical, and clinical evidence that supports the medical professional in deciding which will directly improve their patients' health. The results of the test should be actionable, and the patient's state of health needs to be at the forefront of every diagnostic or therapeutic intervention that is performed. The Reporting Recommendations for Tumour Marker Prognostic Studies (REMARK) checklist was developed as a guide with the items that investigators need to report in their prognostic studies in order to avoid deficiencies that often plague the literature [49]. Secondly, analytical techniques must be sensitive, specific for the biomarker under question, replicable, cost-effective, quick, and user-friendly for the clinical laboratory staff.
Panagiotara/Markou/Lianidou/Patrinos/ Katsila 
Cost-effectiveness is a key aspect of the evaluation of any diagnostic or therapeutic procedure as it guides national health-care systems and private health-care providers towards the adoption and reimbursement of new technologies. For this reason, clinical validated biomarkers paired with low-cost technologies are the gold standard in personalized diagnostics. As mentioned above, there are several techniques which are used to analyze exosomes, so this calls for a wide consensus on the most appropriate low-cost one that can be used in a clinical setting together with a standardized protocol to be followed. For clinical utility to be promptly proven, diagnostic innovation developers need to be provided with more incentives and sponsoring opportunities. These will help drive research and the initiation of clinical studies so as to prove the tests' diagnostic value $[31,32]$. In cases where clinical utility is successfully demonstrated, the next step is to further increase the value of the test to make it more appealing for health-care providers. Consequently, Schneider et al. [2] proposed the use of panels that will include a number of validated biomarkers for screening patients for multiple diseases, assessing risk factors, diagnosing them, and informing them on treatment options. Finally, legislation and regulatory frameworks that are in accordance with new clinical advances are required to introduce them effectively to health-care systems [50]. An interesting fact that is open for discussion is that even though in some countries new medicines are introduced into practice from the day of approval, companion diagnostics have to be approved by different, more complicated regulatory procedures that often deter investigators from pursuing the validity of the test in clinical trials [51].

As with any innovative clinical tool, medical professionals need to be properly educated for the efficient application of this new knowledge. For this reason, the collaboration of oncologists, pathologists, biologists, and geneticists is crucial to train each other and coordinate all the analytical phases of exosomes (same for liquid biopsies) from the moment they are approved by the respective regulatory organizations. In fact, the new diagnostic advances seem to give rise to the new specialty of molecular pathology. The "molecular pathobiologist" is expected to keep a "molecular file" for every patient, containing the results from both tissue and liquid biopsies, from which they will be able to derive the molecular profile of the disease of that patient [52]. This new specialty, although still in its infancy, is anticipated to bridge the gap between basic research and clinical implementation and to pave the way for more accessible personalized health care.

Exosomes: A Cancer Theranostics Road Map

\section{A Complementary Role for Liquid Biopsies (and, in Particular, CTCs)}

Recent advances in microfluidics have resulted in new exosome manipulation techniques, such as immune-affinity-based exosomal trapping, sieving (e.g., nanoporous membranes), and exosomal trapping on porous structures (e.g., nanowire-on-micropillars). All are highly convenient when product purity, reagent volumes, and isolation time are considered [53], yet sieving allows whole blood analysis devoid of any previous treatment [54].

Such advances seem to relate and be complementary to liquid biopsies, especially if CTCs are to be considered. Liquid biopsies were first introduced after the discovery that tumor cells enter and circulate in the bloodstream, after their detachment from primary tumors [55]. The term was originally used to describe CTCs, yet currently it is also used for circulating tumor DNA and exosomes. A liquid biopsy can be obtained from most body fluids (blood, serum, plasma, urine, cerebrospinal fluid, ascites, and pleural effusion), and sampling is followed by genomic or proteomic analysis with methodologies that are highly dependent on the biomarker in question. Their appealing characteristic is the possibility to rapidly detect pathogenic variants associated with resistance mechanisms to therapy which could potentially allow clinicians to modify their therapeutic approaches accordingly before patient relapse. Liquid biopsies have come to fill the gaps of traditional tissue biopsies, as we believe that coupled to imaging analyses they can be used both for diagnosis and disease management. In a very recent review, Bardelli and Pantel [56] have evaluated the suitability of blood-based molecular profiles for early detection and monitoring of minimal residual disease. Moreover, Hofman and Popper [52] have included a simplified yet thorough review of the advantages and disadvantages of both tissue and liquid biopsies and explain their complementarity in the clinic. Especially in patients with metastatic cancer, histological or cytological examination may decrease in prevalence for patient monitoring, since in these cases repetitive sampling is required and is more easily performed with blood samples.

After they detach from primary tumors, CTCs migrate to secondary sites via lymph and blood. Only a small fraction of CTCs will manage to develop into metastasis. CTCs can offer disease mapping in real time and thus, represent a major liquid biopsy player. CTCs are extremely rare, and their count in blood is suggested to reflect the tumor burden, the progression of disease, and the overall survival of the patient [57-59]. To monitor and prevent

Public Health Genomics 2017;20:116-125 121 
the metastatic cascade, CTCs should be detected and characterized early, while sequential CTC measurements allow for efficacy assessment when systemic therapies are considered [60]. CTCs can give important prognostic and predictive value in various solid cancers [61-63], even if they are very heterogeneous within the same patient [64].

CTCs have been implemented for prognosis in various clinical trials for breast [65], colon [66], and prostate cancers [67], and their presence is correlated with decreased progression-free survival and overall survival. The US Food and Drug Administration (FDA; www.fda.gov) has licensed the CellSearch ${ }^{\circledR}$ technology (Menarini Diagnostics, Italy) for metastatic cancer (breast, prostate, and colorectal cancers). This technology uses antibodies against the Epithelial Cell Adhesion Molecule (EpCAM) for the isolation and enumeration of peripheral blood CTCs. Notably, in order to obtain nucleic acid samples of high quality and quantity, strict procedures are required, making companion diagnostics and targeted treatment based solely on them difficult [68]. It is getting clear nowadays that wrongful clinical assumptions and consequences might arise upon CTC enumeration devoid of molecular characterization [69]. Indeed, the molecular analysis of CTCs is anticipated to (a) reveal new therapeutic targets, (b) delineate cancer cell signaling, and (c) explore cancer cell dissemination. Such molecular characterization of CTCs has focused on the gene expression [70-72], DNA methylation $[73,74]$, as well as DNA mutation levels [75, 76]. Currently, there are many large-scale translational studies in progress, which will generate critical data and drive CTC analysis and implementation in the clinic, empowering tailor-made therapeutic strategies [77].

\section{Microfluidics for the CTC Isolation in Cancer Research}

Various technologies and microfluidic devices are now available for CTC isolation [78]. Such devices are characterized by high capture efficiency and high purity of isolated CTCs; their main disadvantage up to now has been the long time needed to run each sample and the low capacity in terms of the peripheral blood volume that they can process in a meaningful time for downstream molecular diagnostic applications.

"CTC-Chip" has been the very first specific microfluidic device for CTC isolation. Described in 2007, "CTCChip" consisted of a silicon chamber, etched with 78,000 anti-EpCAM antibody-coated microposts [79]. However, using this first device a lot of false positive results were detected, as it was verified by the high levels of "CTCs" measured in healthy individuals. The latest development of the same group is the "CTC-iChip," which is a platform that allows for label-dependent or label-independent CTC isolation. Recently, CTC-iChip has been evaluated in an expanded set of both epithelial and nonepithelial cancers (lung, pancreas, prostate, melanoma, and breast cancer). Findings support RNA-based single-cell molecular characterization and clinically standardized morphological and immunohistochemical analyses of high quality [80]. The Parsortix (Angle, PLC), based on microfluidics, is a CE-marked in vitro diagnostic device [81]. This benchtop microfluidic device uses single use disposable cassettes containing a stepped structure the width of which gradually decreases until a critical gap (its narrowest point). Such a critical gap ensures CTC selective enrichment, as CTCs are often larger in size and more rigid than blood cells $[82,83]$.

\section{Conclusions and Future Perspectives}

Microfluidics may empower the isolation, differentiation, and enrichment of particles of extremely similar size and shape via high surface to volume ratios and highly precise fluid control. Today, advances in microfluidics lead to effective exosome separation, complementing liquid biopsies towards new-age theranostics. Detection and characterization are essential to the capture-to-diagnosis path, and thus, current efforts focus on the development of detection techniques $[44,84,85]$. Some methodologies even suggest the preparation-free detection of exosomal RNA from raw cell culture media, allowing for promising biofluid applications [85]. Notwithstanding, reliable and robust evidence concerning the clinical utility, validity, and economic value of microfluidics is of paramount importance before they are implemented in the clinic. For this, a strong collaboration should be envisaged among microfluidic engineers and biologists, clinicians, economists, and policy makers to bridge the gaps and embrace the full technology potential.

\section{Acknowledgements}

Part of this work was supported by a European Commission grant (U-PGx; H2020-668353) to G.P.P.

\section{Disclosure Statement}

The authors declare no conflicts of interest.
Panagiotara/Markou/Lianidou/Patrinos/ Katsila 


\section{References}

1 An T, Qin S, Xu Y, Tang Y, Huang Y, Situ B, Inal JM, Zheng L: Exosomes serve as tumour markers for personalized diagnostics owing to their important role in cancer metastasis. J Extracell Vesicles 2015;4:27522.

2 Schneider D, Bianchini G, Horgan D, Michiels S, Witjes W, Hills R, Plun-Favreau J, Brand A, Lawler M: Establishing the evidence bar for molecular diagnostics in personalised cancer care. Public Health Genomics 2015; 18 . 349-358.

3 Senkus E, Kyriakides S, Penault-Llorca F, Poortmans P, Thompson A, Zackrisson S, Cardoso F: Primary breast cancer: ESMO Clinical Practice Guidelines for diagnosis, treatment and follow-up. Ann Oncol 2013; 24(suppl 6):vi7-vi23

4 Cardoso F, Costa A, Norton L, Senkus E Aapro M, Andre F, Barrios C, Bergh J, Biganzoli L, Blackwell K: ESO-ESMO 2nd international consensus guidelines for advanced breast cancer (ABC2). Breast 2014;23:489502 .

5 Reck M, Popat S, Reinmuth N, De Ruysscher D, Kerr K, Peters S; ESMO Guidelines Working Group: Metastatic non-small-cell lung cancer (NSCLC): ESMO clinical practice guidelines for diagnosis, treatment and follow-up. Ann Oncol 2014;25:iii27-iii39.

6 Horwich A, Parker C, Bangma C, Kataja V; ESMO Guidelines Working Group: Prostate cancer: ESMO Clinical Practice Guidelines for diagnosis, treatment and follow-up. Ann Oncol 2010;21:v129-v133.

7 Labianca R, Nordlinger B, Beretta G, Mosconi S, Mandalà M, Cervantes A, Arnold D; ESMO Guidelines Working Group: Early colon cancer: ESMO Clinical Practice Guidelines for diagnosis, treatment and follow-up. Ann Oncol 2013;24:vi64-vi72.

8 Redzic JS, Ung TH, Graner MW: Glioblastoma extracellular vesicles: reservoirs of potential biomarkers. Pharmgenomics Pers Med 2014;7:65-77.

9 Fenizia F, De Luca A, Pasquale R, Sacco A, Forgione L, Lambiase M, Iannaccone A, Chicchinelli N, Franco R, Rossi A: EGFR mutations in lung cancer: from tissue testing to liquid biopsy. Future Oncol 2015;11:1611-1623.

10 Lewis AR, Valle JW, McNamara MG: Pancreatic cancer: are "liquid biopsies" ready for prime-time? World J Gastroenterol 2016;22: 7175 .

11 Gerlinger M, Rowan AJ, Horswell S, Larkin J, Endesfelder D, Gronroos E, Martinez P, Matthews N, Stewart A and Tarpey P: Intratumor heterogeneity and branched evolution revealed by multiregion sequencing. $\mathrm{N}$ Engl J Med 2012;2012:883-892.

12 Yong E: Cancer biomarkers: written in blood. Nature 2014;511:524-526.

13 Zhang C, Guan Y, Sun Y, Ai D, Guo Q: Tumor heterogeneity and circulating tumor cells. Cancer Lett 2016;374:216-223.
14 Schmidt H, Kulasinghe A, Perry C, Nelson C, Punyadeera C: A liquid biopsy for head and neck cancers. Expert Rev Mol Diagn 2016;16 165-172.

15 Rolfo C, Castiglia M, Hong D, Alessandro R, Mertens I, Baggerman G, Zwaenepoel K, GilBazo I, Passiglia F and Carreca AP: Liquid biopsies in lung cancer: the new ambrosia of researchers. Biochim Biophys Acta 2014;1846: 539-546.

16 Trams EG, Lauter CJ, Salem JN, Heine U: Exfoliation of membrane ecto-enzymes in the form of micro-vesicles. Biochim Biophys Acta 1981;645:63-70.

17 Johnstone RM, Adam M, Hammond J, Orr L, Turbide C: Vesicle formation during reticulocyte maturation. Association of plasma membrane activities with released vesicles (exosomes). J Biol Chem 1987;262:9412-9420.

18 Raposo G, Stoorvogel W: Extracellular vesicles: exosomes, microvesicles, and friends. Cell Biol 2013;200:373-383.

19 Mittelbrunn M, Gutiérrez-Vázquez C, Villarroya-Beltri C, González S, Sánchez-Cabo F, González MÁ, Bernad A, Sánchez-Madrid F: Unidirectional transfer of microRNA-loaded exosomes from $\mathrm{T}$ cells to antigen-presenting cells. Nat Commun 2011;2:282.

20 Kowal J, Tkach M, Théry C: Biogenesis and secretion of exosomes. Curr Opin Cell Biol 2014;29:116-125.

21 Gould SJ, Raposo G: As we wait: coping with an imperfect nomenclature for extracellular vesicles. J Extracell Vesicles 2013;2:20389.

22 Fujita Y, Yoshioka Y, Ochiya T: Extracellular vesicle transfer of cancer pathogenic components. Cancer Sci 2016;107:385-390.

23 Cocucci E, Racchetti G, Meldolesi J: Shedding microvesicles: artefacts no more. Trends Cell Biol 2009;19:43-51.

24 Kalra H, Simpson RJ, Ji H, Aikawa E, Altevogt $\mathrm{P}$, Askenase P, Bond VC, Borràs FE, Breakefield X, Budnik V: Vesiclepedia: a compendium for extracellular vesicles with continuous community annotation. PLoS Biol 2012;10: e1001450.

25 Kim D-K, Kang B, Kim OY, Choi D-s, Lee J, Kim SR, Go G, Yoon YJ, Kim JH, Jang SC: EVpedia: an integrated database of highthroughput data for systemic analyses of extracellular vesicles. J Extracell Vesicles 2013;2: 20384.

26 Mathivanan S, Simpson RJ: ExoCarta: a compendium of exosomal proteins and RNA. Proteomics 2009;9:4997-5000.

27 Schneider A, Simons M: Exosomes: vesicular carriers for intercellular communication in neurodegenerative disorders. Cell Tissue Res 2013;352:33-47.

28 Simpson RJ, Lim JW, Moritz RL, Mathivanan S: Exosomes: proteomic insights and diagnostic potential. Expert Rev Proteomics 2009;6: 267-283.
29 Milane L, Singh A, Mattheolabakis G, Suresh M, Amiji MM: Exosome mediated communication within the tumor microenvironment. J Control Release 2015;219:278-294.

30 Simona F, Laura S, Simona T, Riccardo A: Contribution of proteomics to understanding the role of tumor-derived exosomes in cancer progression: state of the art and new perspectives. Proteomics 2013;13:1581-1594.

31 Naito Y, Yoshioka Y, Yamamoto Y, Ochiya T: How cancer cells dictate their microenvironment: present roles of extracellular vesicles. Cell Mol Life Sci 2017;74:697-713.

32 Hoshino A, Costa-Silva B, Shen T-L, Rodrigues G, Hashimoto A, Mark MT, Molina H, Kohsaka S, Di Giannatale A, Ceder S: Tumour exosome integrins determine organotropic metastasis. Nature 2015;527:329_ 335.

33 Gonzalez E, Falcón-Pérez JM: Cell-derived extracellular vesicles as a platform to identify low-invasive disease biomarkers. Expert Rev Mol Diagn 2015;15:907-923.

34 Cappello F, Logozzi M, Campanella C, Bavisotto CC, Marcilla A, Properzi F, Fais S: Exosome levels in human body fluids: a tumor marker by themselves? Eur J Pharm Sci 2017; 96:93-98.

35 Logozzi M, De Milito A, Lugini L, Borghi M, Calabro L, Spada M, Perdicchio M, Marino ML, Federici C, Iessi E: High levels of exosomes expressing CD63 and caveolin-1 in plasma of melanoma patients. PLoS One 2009;4:e5219.

36 Silva J, Garcia V, Rodriguez M, Compte M, Cisneros E, Veguillas P, Garcia J, Dominguez G, Campos-Martin Y, Cuevas J: Analysis of exosome release and its prognostic value in human colorectal cancer. Genes Chromosomes Cancer 2012;51:409-418.

37 Hoffman RM, Couper MP, Zikmund-Fisher BJ, Levin CA, McNaughton-Collins M, Helitzer DL, VanHoewyk J, Barry MJ: Prostate cancer screening decisions: results from the National Survey of Medical Decisions (DECISIONS study). Arch Intern Med 2009;169: 1611-1618.

38 Mitchell PJ, Welton J, Staffurth J, Mason MD, Tabi Z, Clayton A: Can urinary exosomes act as treatment response markers in prostate cancer? J Transl Med 2009;7:4.

39 Kawakami K, Fujita Y, Kato T, Mizutani K, Kameyama K, Tsumoto H, Miura Y, Deguchi $\mathrm{T}$, Ito $\mathrm{M}$ : Integrin $\beta 4$ and vinculin contained in exosomes are potential markers for progression of prostate cancer associated with taxane-resistance. Int J Oncol 2015;47:384390.

40 Théry C, Amigorena S, Raposo G, Clayton A: Isolation and characterization of exosomes from cell culture supernatants and biological fluids. Curr Protoc Cell Biol DOI: 10.1002/ 0471143030.cb0322s30.
Exosomes: A Cancer Theranostics Road Map
Public Health Genomics 2017;20:116-125 DOI: $10.1159 / 000478253$ 
41 Alvarez ML, Khosroheidari M, Ravi RK, DiStefano JK: Comparison of protein, microRNA, and mRNA yields using different methods of urinary exosome isolation for the discovery of kidney disease biomarkers. Kidney Int 2012;82:1024-1032.

42 Witwer KW, Buzas EI, Bemis LT, Bora A, Lässer C, Lötvall J, Nolte EN, Piper MG, Sivaraman S, Skog J: Standardization of sample collection, isolation and analysis methods in extracellular vesicle research. J Extracell Vesicles 2013;2:20360

43 Jørgensen M, Bæk R, Pedersen S, Søndergaard EK, Kristensen SR, Varming K: Extracellular vesicle $(\mathrm{EV})$ array: microarray capturing of exosomes and other extracellular vesicles for multiplexed phenotyping. J Extracell Vesicles 2013;2:20920.

$44 \mathrm{Im} \mathrm{H}$, Shao H, Park YI, Peterson VM, Castro CM, Weissleder R, Lee H: Label-free detection and molecular profiling of exosomes with a nano-plasmonic sensor. Nat Biotechnol 2014;32:490-495.

45 Mizutani K, Terazawa R, Kameyama K, Kato T, Horie K, Tsuchiya T, Seike K, Ehara H, Fujita Y, Kawakami K: Isolation of prostate cancer-related exosomes. Anticancer Res 2014; 34:3419-3423.

46 Meel R, Krawczyk-Durka M, Solinge W, Schiffelers R: Toward routine detection of extracellular vesicles in clinical samples. Int J Lab Hematol 2014;36:244-253.

47 Bobrie A, Colombo M, Raposo G, Théry C: Exosome secretion: molecular mechanisms and roles in immune responses. Traffic 2011; 12:1659-1668.

48 Parkinson DR, McCormack RT, Keating SM, Gutman SI, Hamilton SR, Mansfield EA, Piper MA, DeVerka P, Frueh FW, Jessup JM: Evidence of clinical utility: an unmet need in molecular diagnostics for patients with cancer. AACR Annu Meet, San Diego, April 2014.

49 Altman DG, McShane LM, Sauerbrei W, Taube SE: Reporting recommendations for tumor marker prognostic studies (REMARK): explanation and elaboration. BMC Med 2012; 10:51.

50 Horgan D, Lawler M, Brand A: Getting personal: accelerating personalised and precision medicine integration into clinical cancer research and care in clinical trials. Public Health Genomics 2015;18:325-328.

51 Horgan D: Access for all: a personalised approach. Public Health Genomics 2016;19: 129-131.

52 Hofman P, Popper HH: Pathologists and liquid biopsies: to be or not to be? Virchows Arch 2016;469:601-609.

53 Liga A, Vliegenthart A, Oosthuyzen W, Dear J, Kersaudy-Kerhoas M: Exosome isolation: a microfluidic road-map. Lab Chip 2015;15: 2388-2394.

54 Kanwar SS, Dunlay CJ, Simeone DM, Nagrath S: Microfluidic device (ExoChip) for on-chip isolation, quantification and characterization of circulating exosomes. Lab Chip 2014;14: 1891-1900.
55 Alix-Panabières C, Pantel K: Circulating tumor cells: liquid biopsy of cancer. Clin Chem 2013;59:110-118.

56 Bardelli A, Pantel K: Liquid biopsies, what we do not know (yet). Cancer Cell 2017;31:172179.

57 Allard WJ, Matera J, Miller MC, Repollet M, Connelly MC, Rao C, Tibbe AG, Uhr JW, Terstappen LW: Tumor cells circulate in the peripheral blood of all major carcinomas but not in healthy subjects or patients with nonmalignant diseases. Clin Cancer Res 2004; 10:68976904.

58 De Bono JS, Scher HI, Montgomery RB, Parker C, Miller MC, Tissing H, Doyle GV, Terstappen LW, Pienta KJ, Raghavan D: Circulating tumor cells predict survival benefit from treatment in metastatic castration-resistant prostate cancer. Clin Cancer Res 2008; 14: 6302-6309.

59 Krebs MG, Sloane R, Priest L, Lancashire L, Hou J-M, Greystoke A, Ward TH, Ferraldeschi R, Hughes A, Clack G: Evaluation and prognostic significance of circulating tumor cells in patients with non-small-cell lung cancer. J Clin Oncol 2011;29:1556-1563.

60 Joosse SA, Gorges TM, Pantel K: Biology, detection, and clinical implications of circulating tumor cells. EMBO Mol Med 2015;7:1-11.

61 Bordi P, Del Re M, Danesi R, Tiseo M: Circulating DNA in diagnosis and monitoring EGFR gene mutations in advanced non-small cell lung cancer. Transl Lung Cancer Res 2015;4:584-597.

62 Lianidou ES, Strati A, Markou A: Circulating tumor cells as promising novel biomarkers in solid cancers. Crit Rev Clin Lab Sci 2014;51: 160-171.

63 Costa DB: Identification of somatic genomic alterations in circulating tumors cells: another step forward in non-small-cell lung cancer? J Clin Oncol 2013;31:2236-2239.

64 Powell AA, Talasaz AH, Zhang H, Coram MA, Reddy A, Deng G, Telli ML, Advani RH, Carlson RW, Mollick JA: Single cell profiling of circulating tumor cells: transcriptional heterogeneity and diversity from breast cancer cell lines. PLoS One 2012;7:e33788.

65 Hayes DF, Cristofanilli M, Budd GT, Ellis MJ, Stopeck A, Miller MC, Matera J, Allard WJ, Doyle GV, Terstappen LW: Circulating tumor cells at each follow-up time point during therapy of metastatic breast cancer patients predict progression-free and overall survival. Clin Cancer Res 2006;12:4218-4224.

66 Cohen SJ, Punt CJ, Iannotti N, Saidman BH, Sabbath KD, Gabrail NY, Picus J, Morse M, Mitchell E, Miller MC: Relationship of circulating tumor cells to tumor response, progression-free survival, and overall survival in patients with metastatic colorectal cancer. J Clin Oncol 2008;26:3213-3221.
67 Danila DC, Heller G, Gignac GA, GonzalezEspinoza R, Anand A, Tanaka E, Lilja H, Schwartz L, Larson S, Fleisher M: Circulating tumor cell number and prognosis in progressive castration-resistant prostate cancer. Clin Cancer Res 2007;13:7053-7058.

68 Lianidou ES: Gene expression profiling and DNA methylation analyses of CTCs. Mol Oncol 2016;10:431-442.

69 Plaks V, Koopman CD, Werb Z: Circulating tumor cells. Science 2013;341:1186-1188.

70 Strati A, Markou A, Parisi C, Politaki E, Mavroudis D, Georgoulias V, Lianidou E: Gene expression profile of circulating tumor cells in breast cancer by RT-qPCR. BMC Cancer 2011;11:422.

71 Markou A, Strati A, Malamos N, Georgoulias V, Lianidou ES: Molecular characterization of circulating tumor cells in breast cancer by a liquid bead array hybridization assay. Clin Chem 2011;57:421-430.

72 Sieuwerts AM, Kraan J, Bolt-de Vries J, van der Spoel P, Mostert B, Martens JW, Gratama J-W, Sleijfer S and Foekens JA: Molecular characterization of circulating tumor cells in large quantities of contaminating leukocytes by a multiplex real-time PCR. Breast Cancer Res Treat 2009;118:455.

73 Chimonidou M, Strati A, Tzitzira A, Sotiropoulou G, Malamos N, Georgoulias V, Lianidou ES: DNA methylation of tumor suppressor and metastasis suppressor genes in circulating tumor cells. Clin Chem 2011;57: 1169-1177.

74 Chimonidou M, Strati A, Malamos N, Georgoulias V, Lianidou ES: SOX17 promoter methylation in circulating tumor cells and matched cell-free DNA isolated from plasma of patients with breast cancer. Clin Chem 2013;59:270-279.

75 Markou A, Farkona S, Schiza C, Efstathiou T, Kounelis S, Malamos N, Georgoulias V, Lianidou E: PIK3CA mutational status in circulating tumor cells can change during disease recurrence or progression in patients with breast cancer. Clin Cancer Res 2014;20:58235834.

76 Forshew T, Murtaza M, Parkinson C, Gale D, Tsui DW, Kaper F, Dawson S-J, Piskorz AM, Jimenez-Linan M, Bentley D: Noninvasive identification and monitoring of cancer mutations by targeted deep sequencing of plasma DNA. Sci Transl Med 2012;4:136ra168136ra168.

77 Bidard F-C, Fehm T, Ignatiadis M, Smerage JB, Alix-Panabières C, Janni W, Messina C, Paoletti C, Müller V, Hayes DF: Clinical application of circulating tumor cells in breast cancer: overview of the current interventional trials. Cancer Metastasis Rev 2013;32:179_ 188.

78 Burtis CA, Ashwood ER, Bruns DE: Tietz Textbook of Clinical Chemistry and Molecular Diagnostics. Amsterdam, Elsevier Health Sciences, 2012. 
79 Nagrath S, Sequist LV, Maheswaran S, Bell DW, Irimia D, Ulkus L, Smith MR, Kwak EL, Digumarthy S, Muzikansky A: Isolation of rare circulating tumour cells in cancer patients by microchip technology. Nature 2007; 450:1235-1239.

80 Ozkumur E, Shah AM, Ciciliano JC, Emmink BL, Miyamoto DT, Brachtel E, Yu M, Chen P-i, Morgan B, Trautwein J: Inertial focusing for tumor antigen-dependent and -independent sorting of rare circulating tumor cells. Sci Transl Med 2013;5:179ra147-179ra147.

$81 \mathrm{Xu}$ L, Mao X, Imrali A, Syed F, Mutsvangwa K, Berney D, Cathcart P, Hines J, Shamash J, Lu Y-J: Optimization and evaluation of a novel size based circulating tumor cell isolation system. PLoS One 2015;10:e0138032.

82 Hou J-M, Krebs M, Ward T, Sloane R, Priest L, Hughes A, Clack G, Ranson M, Blackhall F, Dive C: Circulating tumor cells as a window on metastasis biology in lung cancer. Am J Pathol 2011;178:989-996.
83 Hosokawa M, Kenmotsu H, Koh Y, Yoshino T, Yoshikawa T, Naito T, Takahashi T, Murakami $\mathrm{H}$, Nakamura Y, Tsuya A: Size-based isolation of circulating tumor cells in lung cancer patients using a microcavity array system. PLoS One 2013;8:e67466.

84 Shao H, Chung J, Balaj L, Charest A, Bigner DD, Carter BS, Hochberg FH, Breakefield $\mathrm{XO}$, Weissleder R, Lee H: Protein typing of circulating microvesicles allows real-time monitoring of glioblastoma therapy. Nat Med 2012;18:1835-1840.

85 Taller D, Richards K, Slouka Z, Senapati S, Hill R, Go DB, Chang H-C: On-chip surface acoustic wave lysis and ion-exchange nanomembrane detection of exosomal RNA for pancreatic cancer study and diagnosis. Lab Chip 2015;15:1656-1666.

86 Kharmate G, Hosseini-Beheshti E, Caradec J, Chin MY, Guns EST: Epidermal growth factor receptor in prostate cancer derived exosomes. PLoS One 2016;11:e154967.
87 Rupp A-K, Rupp C, Keller S, Brase JC, Ehehalt R, Fogel M, Moldenhauer G, Marmé F, Sültmann $\mathrm{H}$, Altevogt P: Loss of EpCAM expression in breast cancer derived serum exosomes: role of proteolytic cleavage. Gynecol Oncol 2011;122:437-446.

88 Rabinowits G, Gerçel-Taylor C, Day JM, Taylor DD, Kloecker GH: Exosomal microRNA: a diagnostic marker for lung cancer. Clin Lung Cancer 2009;10:42-46.

89 Manterola L, Guruceaga E, Pérez-Larraya JG, González-Huarriz M, Jauregui P, Tejada S, Diez-Valle R, Segura V, Samprón N, Barrena C: A small noncoding RNA signature found in exosomes of GBM patient serum as a diagnostic tool. Neuro Oncol 2014;16:520-527.

90 Ogata-Kawata $H$, Izumiya $M$, Kurioka $D$, Honma Y, Yamada Y, Furuta K, Gunji T, Ohta H, Okamoto H, Sonoda H: Circulating exosomal microRNAs as biomarkers of colon cancer. PLoS One 2014;9:e92921.

91 Hong C-S, Muller L, Whiteside TL, Boyiadzis M: Plasma exosomes as markers of therapeutic response in patients with acute myeloid leukemia. Front Immunol 2014;5:160.
Exosomes: A Cancer Theranostics Road
Public Health Genomics 2017;20:116-125 DOI: $10.1159 / 000478253$ 